\title{
Congenital unilateral perisylvian syndrome: radiological basis and clinical correlations
}

\author{
G Sébire, B Husson, A Dusser, Y Navelet, M Tardieu, P Landrieu
}

\begin{abstract}
Design-Advances in neuroimaging have allowed correlations between radiological patterns and clinical features of brain malformations. This paper reports clinical, prognosis, and electroencephalographic features of six children with a previously unrecognised neuroimaging picture of unilateral widening and verticalisation of the sylvian fossa associated with an abnormal ipsilateral perisylvian cortex.

Results-All children had reduced hemisphere size and thalamostriatal hypoplasia ipsilateral to the cleft and hemiplegia. Cognitive development was mostly impaired. Epilepsy occurred in two patients and was mainly characterised by partial seizures. Studies with EEG showed hemispheric slowing of background activity homolateral to the perisylvian dysplasia. Occurrence of the malformation among their siblings was not found.

Conclusion-Similar brain malformations occasionally reported in older patients confirm the clinical picture, sporadic occurrence, and prognosis found, allowing the validation of a unilateral perisylvian syndrome.
\end{abstract}

(F Neurol Neurosurg Psychiatry 1996;61:52-56)

Keywords: cerebral palsy; perisylvian dysplasia

Advances in neuroimaging and especially in MRI have allowed the recognition of diffuse as well as localised disorganisation of cortical architecture. Correlations between radiological patterns and clinical features have led to better characterisation of disorders such as bilateral perisylvian syndrome, 12 "double cortex" syndrome, ${ }^{34}$ classic agyria-pachygyria, and atypical lissencephaly. ${ }^{5}$
Over several years, we have identified in our centre a distinct group of six children presenting with unilateral perisylvian structural anomalies on neuroimaging. The clinical and EEG features associated with this radiological pattern, together with a review of cases selected from the medical literature, allowed us to define a "congenital unilateral perisylvian syndrome".

\section{Patients and methods}

Six patients were studied between 1990 and 1994. In five patients, MRI was performed at 0.5 or $1.5 \mathrm{Tesla}$, with $\mathrm{T} 1$ spin echo sequences (TR from 400 to $650 \mathrm{~ms}$, TE from 10 to 40 $\mathrm{ms}$ ), T2 spin echo sequences (TR from 1500 to $4000 \mathrm{~ms}$, late TE from 70 to $120 \mathrm{~ms}$ ) in axial, sagittal, or coronal sections. Two children underwent studies with $\mathrm{T} 1$ weighted inversion recovery sequences (TR from 1500 to $2500 \mathrm{~ms}$, TE $=20 \mathrm{~ms}$, TI from 600 to $1000 \mathrm{~ms}$ ). CT was performed in four patients. All patients fulfilled the following radiological criteria: (a) On one side, presence of a sulcus with the location and shape of a sylvian fossa, but oversized, and extended vertically as shown by the prolongation of the fissure on axial sections, at the top of the lateral ventricle and above; $(b)$ absence of visible communication between the fissure and the ventricle; $(c)$ abnormal appearance of the ipsilateral perisylvian brain parenchyma. Other investigations included EEG studies and developmental screen by the Denver developmental screening test. Karyotyping was performed by standard techniques.

\section{Results}

Mean age at the time of the study was 18 (range 9 to 30 ) months. Consanguinity or clinical evidence of occurrence of the malformation among other siblings were not found (mean sibship: three (range one to seven children). Pregnancy was seriously disturbed at 15
Service de Radiologie B Husson

Service d'Explorations Fonctionelles

Neurologiques Hôpital Bicêtre, Le Kremlin Bicêtre, Paris, France Y Navelet

Correspondence to: Dr G Sébire, Service de Neurologie, Département de Pédiatrie, Hôpital Bicêtre, 78 rue du général Leclerc, 94275, Le Kremlin Bicêtre Cedex, France.

Received 7 August 1995

and in revised form

Accepted 7 February 1996

Table 1 Clinical aspects of unilateral perisylvian dysplasia

\begin{tabular}{|c|c|c|c|c|c|c|c|c|c|}
\hline \multirow[b]{2}{*}{ Patient } & \multirow[b]{2}{*}{$\begin{array}{l}\text { Age } \\
\text { (months) }\end{array}$} & \multirow[b]{2}{*}{ Sex } & \multirow[b]{2}{*}{$\begin{array}{l}\text { Motor } \\
\text { impairment }\end{array}$} & \multirow{2}{*}{$\begin{array}{l}\text { Cognitve } \\
\text { development } \\
D Q(\%)\end{array}$} & \multirow[b]{2}{*}{ Speech } & \multicolumn{2}{|l|}{ Seizures } & \multirow{2}{*}{$\begin{array}{l}\text { Skull } \\
\text { growth }\end{array}$} & \multirow[b]{2}{*}{ Other } \\
\hline & & & & & & Type & Control & & \\
\hline 1 & 22 & $\mathrm{~F}^{\star}$ & $\mathrm{RH}^{\star}$ & 100 & Normal & - & - & Normal & - \\
\hline 2 & 20 & $M^{\star}$ & $\mathrm{LH}^{\star}$ & 50 & Delayed & Spasms & - & $-3 S D$ & - \\
\hline 3 & 9 & $\mathrm{~F}$ & $\mathrm{RLH}$ & 10 & Delayed & & - & Normal & $\begin{array}{l}\text { Death (9 months) } \\
\text { Optic dysplasia }\end{array}$ \\
\hline 4 & 14 & $M$ & $\mathrm{RH}$ & 50 & Delayed & & - & Normal & \\
\hline 5 & 14 & $M$ & $\mathrm{LH}$ & 100 & Normal & Partial & + & Normal & Optic dysplasia \\
\hline 6 & 30 & $\mathrm{~F}$ & $\mathrm{LH}$ & 75 & Delayed & - & - & Normal & \\
\hline
\end{tabular}

*Age at last examination.

$\mathrm{H}=$ Hemiplegia $; \mathrm{L}=$ left; $\mathrm{R}=$ right $; \mathrm{DQ}=$ developmental quotient. 
Figure 1 EEG recorded in patient 5 (1 year old) shows assymetry of background rhythm, slower on the right side. Spike waves are detected in the right occipital region. Calibration: $1 \mathrm{~s}, 50 \mu \mathrm{V}$.

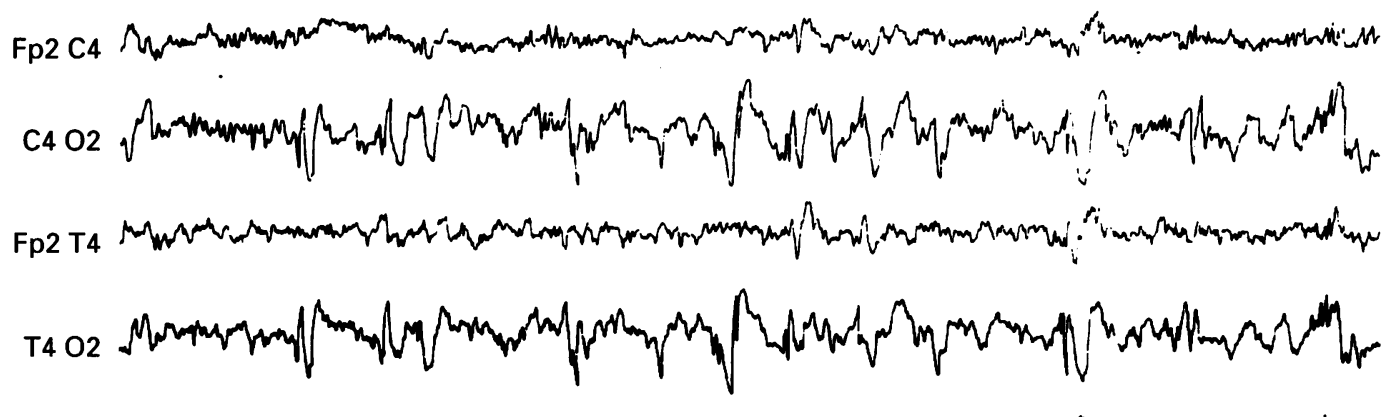

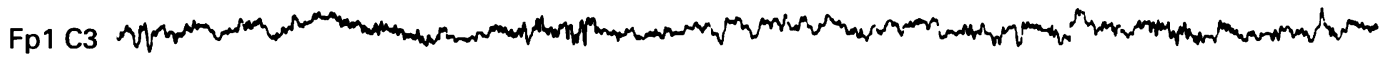

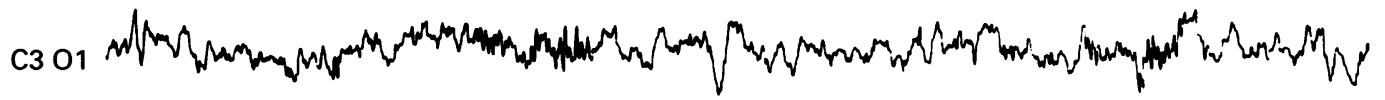

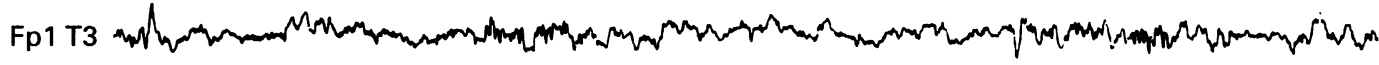

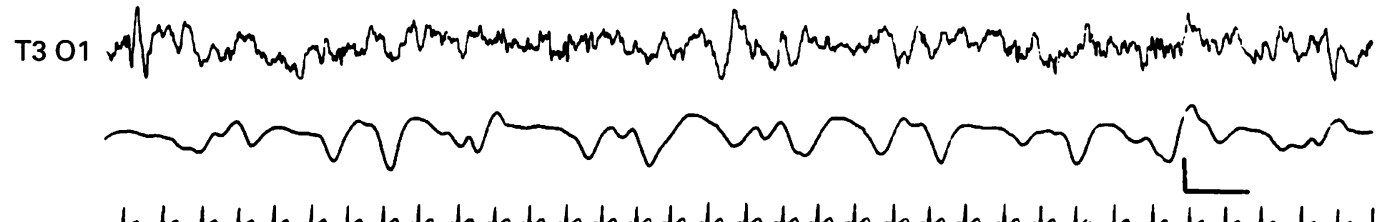

weeks for patient 1 by a car crash causing multiple fractures of the legs in the mother. Pregnancy was normal in the other patients.

Table 1 summarises the clinical features of the six patients. All the children had hemiplegia with pyramidal symptoms contralateral to the brain defect. Among the three patients older than 16 months, two had acquired the ability to walk. Bilateral motor anomalies were detected only in patient 3 , who had a cerebellar hemispheric and vermian hypoplasia in addition to perisylvian dysplasia. Cognitive development was impaired in most patients (four patients with a development quotient $\leqslant 75$ ). Two children (patients 3 and 5) were blind with a pallor of both optic discs. Patient 5 also presented a right optic hypoplasia with the disc a quarter of the normal size. Non-neurological associated malformation was detected in patient 1 (heart malformation: ventricular septal defect).

Epileptic seizures occurred in two patients (table 1), in whom EEG showed active bursts of spikes, spike waves, and slow waves predominantly over central or occipital areas homolateral to the dysplasia; Studies with EEG in other patients mostly showed hemispheric slowing of the background activity ipsilateral to the dysplasia (patients 2,4 , and 5 , fig 1) or bilateral (patient 3).

In patient 3, a chromosome study showed $46 \mathrm{XX}$ inv 9 (p11; q13).

Table 2 and figs 2 and 3 show neuroradiological features. The dysplasic sylvian fossa was enlarged, appearing as a deep cleft directed toward the lateral ventricle, laterally opened and vertically extended in the opercular region. On axial sections the fissure was shaped either as a straight line or as a $\mathrm{Y}$, thus showing partial operculation. All patients, except patient 3, presented with a normal structure of the inferior part of the sylvian fossa. The grey matter surrounding the sylvian fossa was characterised either by a thick cortical ribbon lacking interdigitations between grey and white matter (patients $1,2,4,5$, and 6 ) or by a thin cortex with excessive folding of small convoluted gyri (patient 3). In all patients the hemisphere ipsilateral to the cleft was smaller than the contralateral hemisphere (termed hemispheric hypoplasia in table 2). All patients had thalamostriatal hypoplasia. The extent of striatal hypoplasia was variable, restricted to the putamen in patient 1 , moderate in patients 4 and 6 , and severe in patients 2 , 3 , and 5 (figs 2 and 3). The brain anomalies

Table 2 Radiological aspects of unilateral perisylvian dysplasia

\begin{tabular}{|c|c|c|c|c|c|c|c|}
\hline \multirow[b]{2}{*}{$\begin{array}{l}\text { Patient } \\
\text { No }\end{array}$} & \multirow[b]{2}{*}{ Location } & \multicolumn{3}{|c|}{ Ipsilateral anomalies } & \multirow[b]{2}{*}{$\begin{array}{l}\text { Ventricular } \\
\text { widening }\end{array}$} & \multirow[b]{2}{*}{$\begin{array}{l}\text { Contralateral } \\
\text { anomalies }\end{array}$} & \multirow[b]{2}{*}{ Other features } \\
\hline & & $\begin{array}{l}\text { Perisylvian } \\
\text { macrogyria }\end{array}$ & $\begin{array}{l}\text { Hemispheric } \\
\text { hypoplasia }\end{array}$ & $\begin{array}{l}\text { Basal ganglia } \\
\text { hypoplasia }\end{array}$ & & & \\
\hline 1 & $\mathbf{L}$ & + & + & + & + & - & SA \\
\hline 2 & $\mathbf{R}$ & + & + & + & + & - & \\
\hline 3 & $\mathbf{R}$ & + & + & + & + & - & $\begin{array}{l}\text { Calcifications, } \\
\text { Cerebellar hypoplasia }\end{array}$ \\
\hline 4 & $\mathrm{~L}$ & + & + & + & + & - & \\
\hline 5 & $\mathbf{R}$ & + & + & + & - & - & $\mathrm{CCA}, \mathrm{SA}$ \\
\hline 0 & $\mathbf{K}$ & + & + & + & + & - & SA \\
\hline
\end{tabular}

$\mathrm{CCA}=$ corpus callosum agenesis; $\mathrm{L}=$ left; $\mathrm{R}=$ right; $\mathrm{SA}=$ septal agenesis 


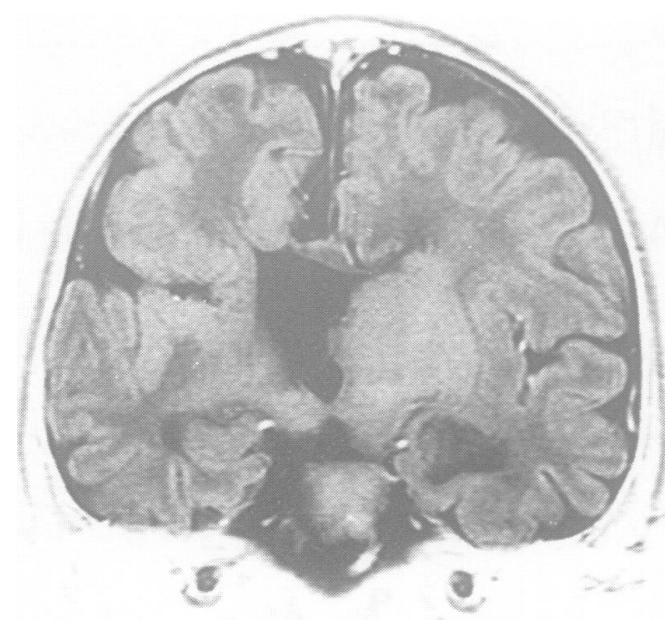

$A$

Figure 2 MRI of patient 5 (3 months old). (A) Coronal section shows enlargement and lack of operculation of the right sylvian fossa which is surrounded by an abnormally thick cortex. The right hemisphere has a reduced size. The septum pellucidum is not visible. The striatum and thalamus are hypoplasic on the right side. The left temporal horn is enlarged with a hypoplasic, vertically oriented hippocampus (T2 spin echo weighted image with inversed contrast improving the anatomical analysis and accounting for the unusual dark aspect of CSF and white matter; TR $=4000 \mathrm{~ms}, T E=90 \mathrm{~ms})$. (B) and (C) Sagittal sections compare the normal aspect of the left sylvian fissure (B) with the verticalised and extended aspect of the right sylvian fissure (C) (T1 spin echo weighted images).

were unilateral, except in patient 5 , who had enlargement of the left temporal horn with a maldeveloped, vertically oriented hippocampus (fig 2A).

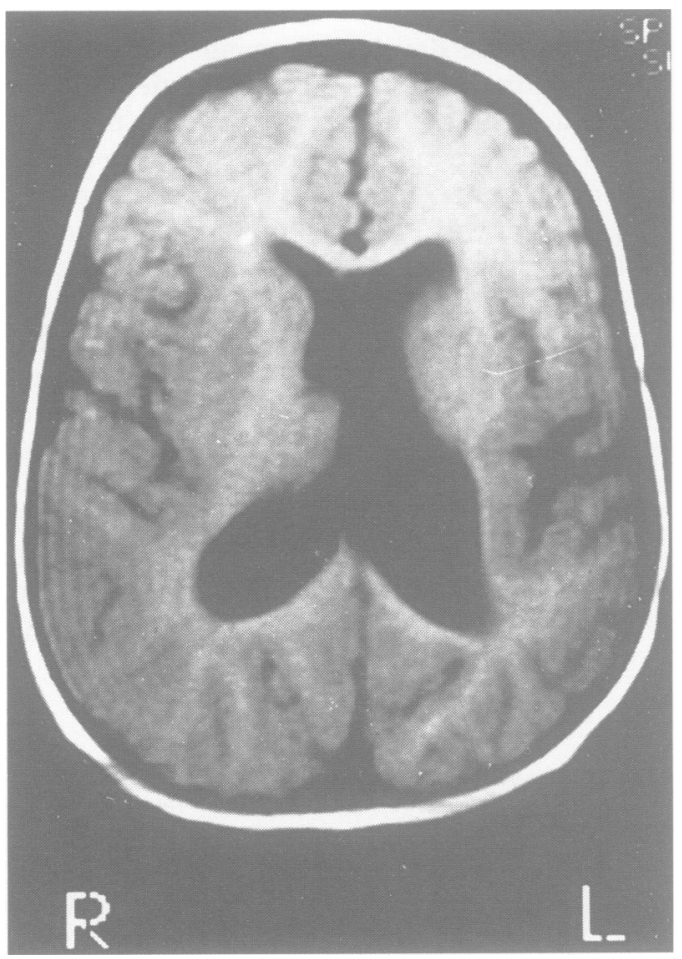

Figure 3 MRI of patient 1 (1 year old): axial section shows enlargement and only partial operculation of the left sylvian fossa (T1 spin echo weighted image). The cortex bordering the cleft is abnormally thick and devoid of interdigitation with white matter. The left striatum is hypoplasic.

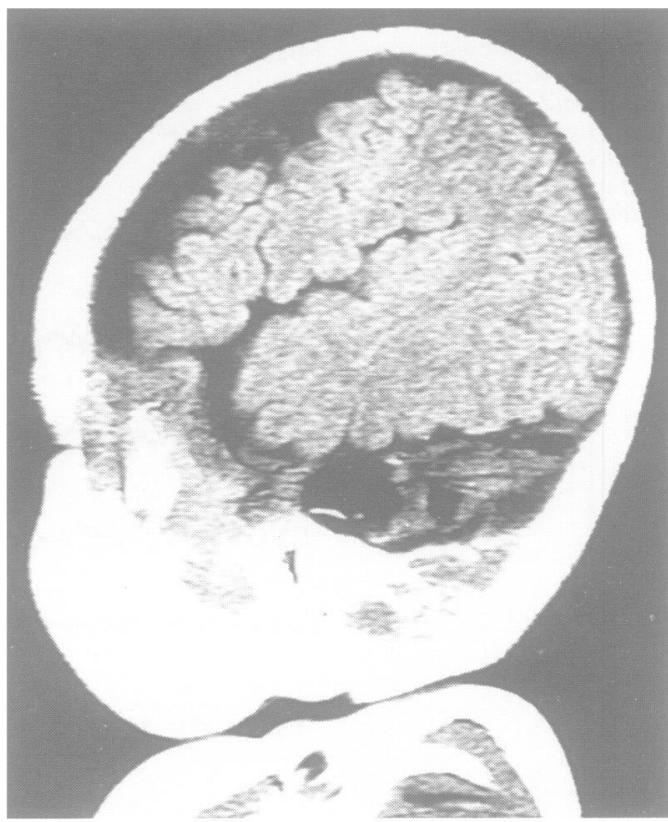

$B$

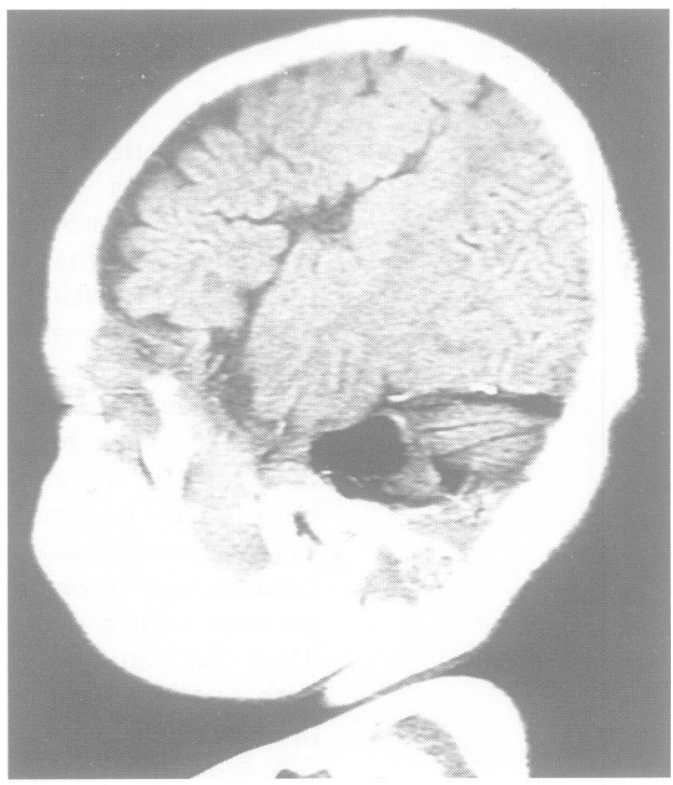

C

\section{Discussion}

The six patients displayed a congenital disorder characterised radiologically by a recognisable unilateral dysplasia of the sylvian region, and clinically by early hemiplegia, impaired cognitive functions, and inconstant epilepsy. Among the classic, clinically defined varieties of cerebral palsy, the present disorder represents a subset of congenital hemiplegia. Curiously, although congenital hemiplegia is frequent, extensively submitted to cerebral imaging, and usually recognised as being the result of prenatal insults, recent clinical works on the subject have not stressed the relevance of unilateral perisylvian dysplasia. ${ }^{6}$ However, in one report of 111 patients with congenital hemiplegia studied by CT, nine patients ( $8 \%$ ) had brain malformations called "focal pachygyria", seemingly corresponding to unilateral perisylvian dysplasia. ${ }^{7}$ Findings similar to those of the present patients have been prefer- 
entially included in radiological reports on heterogeneous groups of brain malformations referred to as "schizencephaly", "focal gyral anomalies", "unilateral opercular neuronal migration disorder", or "porencephaly". ${ }^{8-13}$ From these studies, we selected 13 patients in whom radiological features corresponded with unilateral congenital perisylvian dysplasia (patients 1 to $5,{ }^{8}$ patients 1 and $2,{ }^{9}$ patients 9 and $12,{ }^{10}$ patients 12 and $18,{ }^{11}$ patients 10 and $\left.11,{ }^{12}\right)$. Clinical features, such as motor disability and intellectual performance, were very close to those of our patients. One half of these patients had hemiplegia. Forty per cent had normal intelligence. Three patients had borderline performances with IQ between 80 and 87. The remaining four patients had mental impairment not evaluated by psychometric tests. Interestingly, partial epilepsy was the sole manifestation of unilateral perisylvian dysplasia in three patients. Ninety two per cent had epilepsy, mainly characterised by partial seizures, a proportion higher than in our study. Explanations could come from both recruitment bias and from differences in follow up: the mean age of patients at the last investigation in these reports was 20 (range 5 to 63) years versus 18 (range 9 to 30 ) months in our study. Optic hypoplasia or blindness were not mentioned but finding such an anomaly in the present series is probably just a further indication that septo-optic dysplasia is one possible variant of the encephaloclastic process occurring in mid-gestation.

The unilateral perisylvian dysplasia described here could correspond to the unilateral counterpart of the "bilateral perisylvian syndrome" ${ }^{1}$ In this disorder the radiological features are very similar but the bilateral lesions lead to a special clinical picture dominated by suprabulbar signs and more severe mental retardation and epilepsy. Septo-optic dysplasia seems to be more frequent in unilateral perisylvian dysplasia. Some cases of bilateral perisylvian dysplasia so far reported were clearly asymmetric, ${ }^{1}$ suggesting a continuum between the two syndromes. In our experience however, clearly unilateral cases have been as numerous as bilateral cases, thus the relative incidence of both syndromes is probably more balanced than previously thought.

Unilateral perisylvian dysplasia seems different from other defects of the cerebral mantle such as those termed porencephaly according to Herschtl, ${ }^{1415}$ or schizencephaly according to Yakovlev and Wadsworth. ${ }^{16}{ }^{17}$ Both terms correspond to hemispheric clefts or cavities of developmental origin that extend through the full depth of the hemispheric mantle from the ventricle to the subarachnoid space. Such defects are of large size or of small size, either spanning the whole cerebral mantle or separated from the ventricle by a thin layer of tissue with a virtual cleft, the two walls of the lesion being apposed to form a pia-arachnoid seam. ${ }^{1617}$ The central region is the most typical location of the cleft but the frontal or any other region can be involved as well. ${ }^{14}$ In the central region, differentiating a true porencephalic cleft from a deeply enlarged and dys- plasic sylvian fossa would be an academic exercise, as the anatomical rearrangements are mainly dependent on the severity and precocity of the pathological process. Moreover, the abnormal anatomical morphology of the adjacent cortex, mostly corresponding to polymicrogyria and neuronal depopulation, appears very similar in both classic porencephaly and perisylvian dysplasia. ${ }^{14}$ Other lesions such as thalamic hypoplasia and septal agenesis also appear often in classic porencephaly..$^{121415} \mathrm{On}$ the other hand, alterations in gyral development, indicated by abnormal cortical ribbon on imaging, distinguish perisylvian dysplasia from encephaloclastic lesions originating during the terminal phase of pregnancy or during postnatal life such as perinatal stroke or cystic lesion from perinatal haematoma, which destroy cortical tissue without altering gyral development.

Cause and timing of the pathological mechanisms leading to hemispheric clefts or to perisylvian dysplasia remain controversial. Previous major hypotheses were either a localised disturbance of neuronal proliferation or migration, ${ }^{1617}$ or a destructive process occurring during the last stage or after completion of migration - that is, between the third and sixth month of gestation. ${ }^{18-20} \mathrm{~A}$ hypothesis of a true ontogenic defect of brain development seems unlikely. Sporadic occurrence, asymmetry of brain defect, encephaloclastic appearance of the microscopic morphology, and reports of cases probably related to casual events make the second hypothesis more convincing. ${ }^{2122}$ Cellular death can be induced by multiple causes, from purely accidental to genetic, such as anoxia (vasculopathy, systemic hypotension, vascular embolism or thrombosis), haemorrhage, infection, trauma, and intoxication..$^{23}$ Direct recording of pathological events occurring during gestation will be necessary to advance our understanding.

We thank L Outin and M Thoma for their excellent assistance.

1 Kuzniecky R, Andermann F, Guerrini R and the CBPS Multicenter Collaborative Study. Congenital bilatera perisylvian syndrome: study of 31 patients. Lancet 1993 341:608-12.

2 Kuzniecky R, Andermann F, Guerrini R and the CBPS Multicenter Collaborative Study. The epileptic spectrum in the congenital bilateral perisylvian syndrome. Neurology 1994;44:379-85.

3 Palmini A, Andermann F, Aicardi J, et al. Diffuse cortical dysplasia, or the "double cortex" syndrome: the clinical and epileptic spectrum in 10 patients. Neurology 1991, and epileptic

4 Barkovich AJ, Guerrini R, Battaglia G, et al. Band heterotopia: correlation of outcome with magnetic resonance imaging parameters. Ann Neurol 1994;36:609-17.

5 Sébire G, Goutières $F$, Tardieu M, Landrieu P, Aicardi J. Extensive macrogyri and/or no visible gyri: distinct clinical, electro-encephalographical and genetic features according to different imaging patterns. Neurology 1995;45: $1105-11$

6 Aicardi J, ed. Cerebral palsy. In: Diseases of the nervous system in childhood. London: MacKeith Press, 1992: 330-74.

7 Wiklund LM, Uvebrant P, Flodmark O. Morphology of cerebral lesions in children with congenital hemiplegia. Neuroradiology 1990;32:179-86.

8 Aniskiewicz AS, Frumkin NL, Brady DE, Moore JB, Pera A. Magnetic resonance imaging and neurobehavioral corA. Magnetic resonance imaging and neurobehavioral cor-
relates in schizencephaly. Arch Neurol 1990;40:911-6.

9 Ambrosetto G. Treatable partial epilepsy and unilateral opercular neuronal migration disorder. Epilepsia 1993; opercular

10 Guerrini R, Dravet C, Raybaud C, et al. Epilepsy and focal gyral anomalies detected by MRI: electroclinico-morphological correlations and follow-up. Dev Med Child Neurol 1992;34:706-18. 
11 Menezes L, Aicardi J, Goutières F. Absence of the septum pellucidum with porencephalia. A neuroradiologic syn1988;45:542-5.

12 Barkovich AJ, Kjos BO. Schizencephaly: correlation of clinical findings with MR characteristics. AfNR $A m \mathcal{F}$ Neuroradiol 1992;13:85-94.

13 Miller GM, Stears JC, Guggenheim MA, Wilkening GN. Schizencephaly: a clinical and CT study. Neurology 1984;34:997-1001.

14 Friede RL, ed. Porencephaly, hydranencephaly, multicystic encephalopathy. In: Developmental neuropathology. Berlin: Springer Verlag, 1991:28-30.

15 Aicardi J, Goutières F. The syndrome of absence of the septum pellucidum with porencephalies and other developmental defects. Neuropediatrics 1981;12:319-29.

16 Yakovlev PI, Wadsworth RC. Schizencephalies. A study of the congenital clefts in the cerebral mantle. I. Clefts with fused lips. $\mathcal{F}$ Neuropathol Exp Neurol 1946;5:116-30.

17 Yakovlev PI, Wadsworth RC. Schizencephalies. A study of the congenital clefts in the cerebral mantle. II. Clefts with hydrocephalus and lips separated. $\mathcal{F}$ Neuropathol Exp
Neurol 1946;5:169-205.

8 Dekaban A. Large defects in cerebral hemisphere associated with cortical dysgenesis. F Neuropathol Exp Neurol 1965;24:512-30.

19 Lyon G, Robain O. Etude comparative des encéphalopathies circulatoires prénatales et paranataleshydranencéphalies, porencphalies et encéphalopathies kystiques de la substance blanche. Acta Neuropathol 1963;9:79-98.

20 Levine DN, Fisher MA, Caviness V. Porencephaly with microgyria, a pathological study. Acta Neuropath 1974; 29:99-113

21 Bordarier C, Robain O, Ponsot G. Bilateral porencephalic defect in a newborn after injection of benzol during pregnancy. Brain Dev 1991;13:126-9.

22 Dominguez R, Vila-Coro AA, Slopis JM, Bohan TP. Brain and ocular abnormalities in infants with in utero exposure to cocaine and other street drugs. $A \mathcal{F} D C$ 1991; 145:688-95.

23 Landrieu P, Lacroix C. Schizencephaly, consequence of a developmental vasculopathy? A clinicopathological report. Clin Neuropathol 1994;13:1-5.

\section{Gerstmann's syndrome}

In the 19th century, there flourished the concept of localising organic function to discrete areas or "centres" in the brain. It was extended to attempts to provide accurate localisation for the more problematical higher cortical and psychological dysfunctions. Of many such syndromes described at the turn of the 20th century, the syndrome of Gerstmann is a good and oft cited example:

"The subject of this paper... I first described several years ago $(1924)^{1}$ under the name of 'finger agnosia'. It manifests itself as an isolated disturbance in the recognition, naming, choosing, and differential exhibition of the various fingers of both hands-one's own fingers as well as those of another person. . . . Furthermore, I will discuss the association that I noted between this symptom and a disturbance in right-left orientation (in one's own as well as in another's body), agraphia and acalculia.

... in some it existed as an independent condition from the beginning, while in others-though seldom-it was a residual syndrome after regression of a more complex deficit.

... In its selective form .... aphasia, apraxia, agnosia have been lacking. Furthermore, the other signs that have sometimes been associated with the syndrome (such as right hemianopsia, diminution of opticokinetic nystagmus, amnestic disturbance of word-finding, impairment in reading ability, ...) can be characterised as neighbouring or bordering symptoms because of their variable appearance and mildness. The phenomenon of finger agnosia itself always appeared as an essential disturbance of recognition and orientation.

.. It has become evident that the syndrome of finger agnosia, agraphia etc can be related to a focal disturbance in the area of transition between the angular and second occipital convolution.... the syndrome . . . is caused by a unilateral lesion in the left hemisphere in right-handed individuals."2

Gerstmann referred to corroborative cases of Pötzl and Herrmann, Schilder, Kroll, and Lange; the syndrome found acceptance in the contemporary corpus of neurological teaching, but was later seriously challenged.

The entity proclaimed by Gerstmann has been seriously arraigned, notably by Critchley in a classic and critical review. ${ }^{3} \mathrm{He}$ demurred at the idea of an autonomous, independent syndrome, and at its alleged localising value. Benton too, harshly but probably justly, regarded it: "an artifact of defective and biased observation having little support for its alleged foca diagnostic significance." 4 Further, the description was not original: Anton (1899) and Hartmann (1902) described similar cases (though with bilateral pathology and therefore not strictly comparable). Critchley assigned priority to Jules Badal, ophthalmologist in Bordeaux, who in 1888 accurately reported the essential features in a patient named Valérie, suffering the posteclamptic state.

Josef Gerstmann (1887-1969) of Vienna was a pupil of the Nobel prize winner Wagner von Jauregg; he became professor of neurology and psychiatry and director at the Maria-Thereisen-Schlossel. He fled the oncoming Nazi regime in 1938, but continued his work in the United States and wrote several papers on the variation of symptoms, pathology, and the localising value of his syndrome.

1 Gerstmann J. Fingeragnosie: Eine umschriebene Störung der Orientierung am eigenen Körper. Wien klin Wschr 1924;37:1010-2

2 Gerstmann J. Zur Symptomatologie der Hirnläsionen im bergangsgebiet der unteren Parietal-und mittleren Occipitalwindung. (Das Syndrom: Fingeragnosie, Rechts-Links-Störung, Agraphie, Akalkulie). Nervenarzt 1930;3:691-5.

3 Critchley $M$. The enigma of Gerstmann's syndrome. Brain 1966;89:183-98.

Benton AL. The fiction of Gerstmann's syndrome. $f$ Neurol Neurosurg Psychiatry 1961;24:176-9.

Badal J. Arch Ophthal (Paris) 1888, 8:97 cited by Critchley. ${ }^{3}$

I S PEARCE 304 Beverley Road, Anlaby Beverley Road, Anlaby 